\title{
CONSIDERAȚII DESPRE CÂTEVA REPLICI ALE TEZAURULUI DE LA PIETROASA
}

\section{CHRISTINA ŞTIRBULESCU}

\section{REFLECTIONS ON SOME COPIES OF THE TREASURE OF PIETROASA}

In three letters, stored in the State Archives of Sigmaringen, King Carol I (Charles I) of Romania mentions the presents offered on Christmas day to his parents and elder brother (prince Karl-Anton and princess Josephine of Hohenzollern-Sigmaringen and, respectively, Leopold of Hohenzollern-Sigmaringen). The pieces gifted to his family are vessels copied (by Paul Telge) after the renowned Late Antiquity gold treasure of Pietroasa. In one letter Carol I wrote about the similar pieces offered to Franz Joseph I, the Austro-Hungarian emperor.

Keywords: treasure, copies, Carol I, presents, Paul Telge.

Cuvinte cheie: tezaur, replici, Carol I, cadouri, Paul Telge.

Tezaurul de la Pietroasa este nu numai cea mai celebră descoperire de pe teritoriul României, dar a fost de multe ori copiat în decursul secolului al XIX-lea. Existența unor epistole scrise de regele Carol I al României, care fac referință la utilizarea replicilor tezaurului, ne determină să scriem aceste rânduri.

Tezaurul de la Pietroasa ${ }^{1}$ a fost descoperit întâmplător în anul 1837 de doi țărani, în timpul activității de extragere a calcarului și a gresiei de pe dealul Istrița ${ }^{2}$. Din cauza mai multor întâmplări nefericite $^{3}$, tezaurul suferă distrugeri însemnate și din cele, probabil, $22^{4}$ de piese existente (vase și podoabe) în momentul descoperirii, s-au păstrat doar $12^{5}$.

Datorită insistențelor banului Mihalache $\mathrm{Ghica}^{6}$, un pasionat colecționar de antichități, se realizează și prima restaurare a pieselor în toamna anului 1838, de către bijutierul Bisterfeld ${ }^{7}$.

Pictorul Ion Negulici desenează în mărime naturală piesele tezaurului, care vor fi litografiate la Viena în 1838 și pe care Banul Mihalache Ghica le va trimite savanților europeni ${ }^{8}$.

Dar tezaurul a intrat cu adevărat în circuitul științific european în deceniul $7^{9}$ al secolului al XIX-lea, cu doar câțiva ani mai devreme de inaugurarea Expoziției Universale din anul $1867^{10}$, de la Paris, atunci când popularitatea lui a fost sporită și extinsă la nivelul societății europene. În acest moment, cele 12 piese ale tezaurului, împreună cu multe alte piese importante de factură arheologică, au fost expuse în cadrul Pavilionului românesc. Comisarul general al secțiunii românești din cadrul manifestării a fost Alexandru Odobescu ${ }^{11}$ (1834-1895), de altfel, unul dintre cei care și-au dedicat o bună parte din activitatea științifică studierii tezaurului de la Pietroasa.

${ }^{1}$ Com. Pietroasele, jud. Buzău. Datorită prezenței printre piese și a unor fibule care reprezintă păsări stilizate, tezaurul a intrat în conștiința colectivă națională cu denumirea „Cloșca cu puii de aur”.

2 Vezi Săndulescu et alii 1967.

3 În general, Odobescu 1976 (1889), 83 (1)-95 (13), 120 (38)-129 (47), 143 (61)-146 (64); Oanţă-Marghitu 2010, 95-96; OanţăMarghitu 2013, 598. Despre stabilirea identității etnice a proprietarilor tezaurului antic, vezi Oanță-Marghitu 2010, 602.

${ }^{4}$ Odobescu 1976 (1889), 93 (11)., ,...] la collection trouvée à Pétrossa se composait primitivement de vingt-deux pièces en or [...]. Neuf seulement d'entre elles furent retrouvées le 17-29 juillet (n.a. 1838) dans les cachettes désignées par Vérussi ; elles forment, avec les trois objets qui avaient été déjà livrés aux autorités, l'ensemble des douze pièces que nous possédons".

${ }^{5}$ Farfuria (patera), cana (oenochoe), platou mare (lanx), două vase poligonale, fibula mare, două fibule mijlocii, fibula mică, colan incrustat cu pietre, două colane din bară de aur, vezi Oanţă-Marghitu 2013, 599-600.

${ }^{6}$ Banul Mihalache Ghica (1796-1850), ministru de interne, membru al Societății de Istorie și Antichități de la Odessa.

7 Vezi Ciucă 2010, 238, nr. 139; 239-240, nr. 141; 293, nr. 194. Plata restaurării (suma de 40 de galbeni) a fost achitată de Eforia Școalelor, vezi Ciucă 2010, 238.

${ }^{8}$ Vezi Odobescu 1976 (1889), 111 (29), dar și Odobescu 1976 (1889), 112 (30)-114 (32).

${ }^{9}$ de Linas 1864, 82-83, 88, 90, pl. 6/A-C; de Linas 1868a, 183-197; de Linas 1868b, 46-56; Bock 1868, 105-124 (bibliografie preluată din M. Babeş, în Odobescu 1976 (1889), p. 7-10); Soden-Smith 1869, apud M. Babeş, în Odobescu 1976 (1889), 9 , nota 34 .

${ }^{10}$ Deschisă în perioada 1 aprilie-3 noiembrie; organizată sub patronajul împăratului Napoleon al III-lea al Franței.

${ }^{11}$ Profesor de arheologie (Universitatea din București), arheolog, scriitor, ministru. 
Interesul pronunțat în societatea românească a secolului al XIX-lea pentru importanța istorică și frumusețea tezaurului de la Pietroasa este dovedit și de scrisorile regelui Carol I al României (18661914) adresate mamei ${ }^{12}$ sale și fratelui ${ }^{13}$ său, la reședința acestora din Sigmaringen. Astfel, în patru epistole trimise în perioada 1885-1905, regele Carol I amintește drept cadouri de Crăciun trimise la Sigmaringen replicile unor piese din tezaurul mai sus menționat. Acestea sunt realizate de Paul Telge ${ }^{14}$, orfevru și bijutier al Casei regale a României în perioada domniei lui Carol I, care în anul 1884 a lucrat la repararea și restaurarea valorosului tezaur ${ }^{15}$.

În martie 1884 piesele tezaurului suferă noi deteriorări ca urmare a incendiului ${ }^{16}$ care a afectat clădirea Universității ${ }^{17}$ din București. Pentru a fi salvat, a fost aruncat pe fereastră.

La invitația autorităților române, Paul Telge vine la București unde "[...] il a soigneusement copié dans des fac-similés fort exacts les douze pièces ${ }^{18 "}$.

Astfel, în a doua jumătate a anului 1884 (cel mai probabil începând din luna iulie ${ }^{19}$ ), tezaurul este trimis la Berlin, pentru a intra într-un proces minuțios de restaurare ${ }^{20}$.

$\mathrm{Cu}$ această ocazie, meșterul german a realizat și un număr de replici ale tuturor pieselor componente $^{21}$. Dintre acestea, copiile reprezentând platoul mare (lanx), vasele poligonale, farfuria (patera) și cana (oenochoe) sunt oferite familiei de la Sigmaringen cu ocazia sărbătoririi Crăciunului în anii $1885^{22}, 1897^{23}$ și $1905^{24}$.

Dar, regele Carol I nu se limitează doar la cadourile către familie, astfel în anul $1896^{25}$, cu ocazia vizitei oficiale a împăratului Franz Josef I (1848-1916) la București, acesta primește în dar de la cuplul regal român „o tavă de aur pentru pâine și sare” și un vas asemănător cu o „solniță aurită”. Carol I dăruiește un exemplar identic celei din urmă și fratelui său, principele Leopold ${ }^{26}$.

Ca ilustrare a valorii deosebite a tezaurului, dar și a execuției artistice desăvârşite, Franz Josef I, împăratul Austro-Ungariei, este primit de oficialități, în gara din București, cu pâine și sare așezate „pe o tavă şi în vase copiate după tezaurul de la Pietroasa"27.

Regele Carol I consideră replicile atât de frumoase, încât îi trimite și cumnatei sale cănile (oenochoe) copiate după cele din tezaur și le consideră demne de a fi expuse alături de vasele primite de la tatăl $\mathrm{ei}^{28}$.

În scrisorile sale, regele Carol I nu menţionează niciodată numele lui Paul Telge.

În afara reproducerii integrale a tezaurului din 1884, mai sunt și alte acțiuni de copiere a unor piese $^{29}$. Cea mai cunoscută este cea din anul 1868, cu ocazia expunerii lor la South Kensington Museum din Londra $^{30}$, azi Victoria\&Albert Museum. Conducerea muzeului aprobă reproducerea prin

\footnotetext{
12 Principesa Josephine de Hohenzollern-Sigmaringen (1813-1900).

${ }^{13}$ Principele Leopold de Hohenzollern-Sigmaringen (1835-1905).

${ }^{14}$ Pentru activitatea lui Telge, vezi Odobescu 1976 (1889), 127 (45), nota 1; Mălăncioiu 2016, 74.

${ }^{15}$ Vezi raportul lui Telge referitor la modalitățile de restaurare ale pieselor după distrugerile la care a fost supus anterior, vezi Ciucă 2010, 363-369, nr. 241.

${ }^{16}$ Jurnal Carol I, 289 (sâmbătă, 24 martie/5 aprilie).

${ }^{17}$ Aici își avea sediul Muzeul National de Antichități (a funcționat în perioada 1864-1931) din al cărui patrimoniu făcea parte, vezi Babeş 2003-2005, 10, 12, fig. 3.

${ }^{18}$ Odobescu 1976 (1889), 127 (45), nota 1.

${ }^{19}$ Telge specifică în raportul său că preferă să lucreze piesele în luna iulie, vezi Ciucă 2010, 368.

${ }^{20}$ Oanţă-Marghitu 2010, 95-96; Oanţă-Marghitu 2013, 599. Telge lucrează la solicitarea guvernului României, Ciucă $2010,363$.

${ }^{21} \mathrm{O}$ copie integrală a tezaurului se află în patrimoniul Muzeului Județean Buzău, vezi http://www.muzeubuzau.ro/arheologie/tezaurulde-la-pietroasele

${ }^{22}$ Cristescu 2012, 120, scrisoarea nr. 45.

${ }^{23}$ Cristescu 2012, 368, scrisoarea nr. 215.

${ }^{24}$ Cristescu 2012, 518, scrisoarea nr. 294.

${ }^{25}$ Cristescu 2012, 355, scrisoarea nr. 209.

${ }^{26}$ Cristescu 2012, 368, scrisoarea nr. 215.

${ }^{27}$ Cristescu 2012, 355, scrisoarea nr. 209.

${ }^{28}$ Cristescu 2012, 518, scrisoarea nr. 294. Este vorba despre Ferdinand al II-lea, regele Portugaliei.

${ }^{29}$,[...] en dehors de la patère V et de l'anneau à inscription III, déjà plusieurs fois moulés antérieurement”, vezi Odobescu 1976 (1889), p. 127 (45), nota 1.

${ }^{30}$ În perioada decembrie 1867-mai 1868, vezi Odobescu 1976 (1889), 127 (45); raportul lui Al. Odobescu, vezi Ciucă 2010 , 337-339, nr. 228.
} 
galvanoplastie ${ }^{31}$ a șase piese: platoul (lanx), cana (oenochoe), patera, colanul incrustat cu pietre, fibula mare și vasul dodecagonal ${ }^{32}$.

De remarcat în acest moment este faptul că regele Carol I selectează din copiile realizate de Telge doar vasele care pot fi incluse în servicii de masă sau care pot fi expuse în cabinete ${ }^{33}$, alături de colecții deja constituite.

Într-un secol în care pangermanismul era în plină înflorire, mărturiile arheologice ale populațiilor germanice din Antichitate, în special ale goților, au ridicat un interes sporit în societatea germană a recent unificatului Imperiu German.

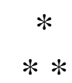

În rândurile de mai jos expunem câteva fragmente din cele patru scrisori, în ordine cronologică, din fondul familiei Hohenzollern din Arhivele Statului de la Sigmaringen.

- Cristescu 2012, 120, scrisoarea nr. 45 (către fratele său, principele Leopold de HohenzollernSigmaringen), București, 2/14 ianuarie 1885.

Despre cadourile de Crăciun.

„Pentru Tata ${ }^{34}$ am comandat o copie după Tezaurul de la Pietroasa, dar până azi n-am putut so primesc și de aceea n-am cum s-o trimit împreună cu cadourile destinate Mamei ${ }^{35}$ ".

- Cristescu 2012, 355, scrisoarea nr. 209 (către mama lui, principesa Josephine de HohenzollernSigmaringen), castelul Peleș, 25 septembrie/7 octombrie 1896.

Descrie momentul în care el, regina Elisabeta a României și împăratul Franz Josef I ajung în gara din București.

„Pe aripa stângă a gărzii se afla primarul ${ }^{36}$ și consiliul municipal care au oferit pâinea și sarea pe o tavă și în vase copiate după tezaurul de la Pietroasa - adevărate opere de artă."

- Cristescu 2012, 368, scrisoarea nr. 215 (către fratele său, principele Leopold de HohenzollernSigmaringen), București, 2/14 ianuarie 1897.

Despre cadourile de Crăciun.

„Pentru tine este solnița aurită - o reproducere fidelă a unei piese din tezaurul de la Pietroasa - una asemănătoare împreună cu o tavă de aur pentru pâine și sare au fost oferite împăratului austriac".

- Cristescu 2012, p. 518, scrisoarea nr. 294 (către fratele său, principele Leopold de HohenzollernSigmaringen), București, 27 decembrie 1904/9 ianuarie 1905.

Despre cadourile de Crăciun.

„Mă bucur că v-au plăcut cănile din tezaurul de la Pietroasa, cred că Antoaneta ${ }^{37}$ le va alătura splendidelor vase din colecția tatălui ei”.

\footnotetext{
31 Tehnică numită și ,electrotype”, vezi Newman 2000, 236.

${ }^{32}$ Odobescu 1976 (1889), 127 (45).

${ }^{33}$ Cristescu 2012, 518, scrisoarea nr. 294.

${ }^{34}$ Principele Karl-Anton de Hohenzollern-Sigmaringen (1811-1885).

${ }^{35}$ Principesa Josephine de Hohenzollern-Sigmaringen (1813-1900).

36 În 1896 primarul orașului București era Constantin F. Robescu, Vitan 2009, 170-177.

${ }^{37}$ Principesa Antonia de Hohenzollern-Sigmaringen (1845-1913).
} 
Babeş 2003-2005

Bock 1868

Ciucă 2010

Cristescu 2012

Jurnal Carol I

de Linas 1864

de Linas 1868a

de Linas $1868 b$

Mălăncioiu 2016

Newman 2000

Oanţă-Marghitu 2010

Oanţă-Marghitu 2013

Odobescu 1976 (1889)

Săndulescu et alii 1967

Soden-Smith 1869

Vitan 2009
M. Babeş, 170 de ani de arheologie românească, SCIVA, 54-56, 2003-2005, p. $9-20$

Fr. Bock, Der Schatz des Westgothenkönigs Athanarich, gefunden im Jahre 1837 zu Petreosa in der grossen Walachei, în Mittheilungen der k. k. CentralCommission zur Erforschung und Erhaltung der Baudenkmale, XIII, 1868, p. 105-124

M.-D. Ciucă, Tezaurul de la Pietroasa. Dosarul descoperirii și al destinului său ulterior (1838-1956), București, 2010

S. Cristescu, Scrisorile regelui Carol I din arhiva de la Sigmaringen (18781905), București, 2012

Jurnal. Carol I al României, vol. I, 1881-1887, stabilirea textului, traducere din limba germană, studiu introductiv și note de Vasile Docea, Iași, 2007

Ch. de Linas, Orfèvrerie mérovingienne. Les auvres de Saint Éloi et la verroterie cloisonnée, Paris, 1864

Ch. de Linas, L'histoire du travail à l'Exposition universelle de 1867, ArrasParis, 1868

Ch. de Linas, Trésor de Pétrossa, Revue Archéologique, N.S., anul IX, vol. XVII, 1868, p. 46-56

Raluca Mălăncioiu, Fructieră lucrată de Paul Telge pentru Carol I, în C. Ilie (coordonator), Capodopere din patrimoniul Muzeului Național de Istorie a României/2016/Masterpieces from the Collection of the National History of Romania/2016, Muzeul Național de Istorie a României/The National History Museum of Romania, Bucuresti, 2016, p. 70-77

H. Newman, An Illustrated Dictionary of Jewelry, Londra, 2000

Rodica Oanţă-Marghitu, Il tesoro di Pietroasa, în E. Oberländer-Târnoveanu, Lucrezia Ungaro (eds.), Ori antichi della Romania. Prima e dopo Traiano, Catalog de expozitie, Roma, 2010, p. 95-104

Rodica Oanţă-Marghitu, Tezaurul de la Pietroasa, com. Pietroasele, jud. Buzău, în Rodica Oanţă-Marghitu (ed.), Aurul și argintul antic al României, catalog de expoziție, Muzeul Național de Istorie a României, București, 2013, p. 598-606

Tezaurul de la Pietroasa, în Al. Odobescu, Opere IV, M. Babeş (ed.), București, 1976

M. Săndulescu, C. Ghenea, I. Motaş, T. Bandrabur, Harta geologică, scara 1:200000, foaia Ploiești, Notă explicativă, Comitetul de Stat al Geologiei, Institutul Geologic, 1967, București

R. H. Soden-Smith, Examples of Art-Workmanship of Various Ages and Countries. The Treasure of Petrossa and other Goldsmith's Work from Roumania, published by the Arundel Society, Londra, 1869

I. Vitan, Primarii Bucureștilor 1864-1949, București, 2009.

CHRISTINA ŞTIRBULESCU, Muzeul Național de Istorie a României, christina_stirbulescu@yahoo.com 